\title{
Stable personal attributes and a resilient approach to work and career
}

\begin{tabular}{|c|c|}
\hline $\begin{array}{l}\text { Authors: } \\
\text { Jill Flint-Taylor } \\
\text { Alex Davda } \\
\text { Cary L. Coope }\end{array}$ & \\
\hline \multicolumn{2}{|c|}{$\begin{array}{l}\text { Executive Development, } \\
\text { Ashridge Business School, } \\
\text { United Kingdom }\end{array}$} \\
\hline \multicolumn{2}{|c|}{$\begin{array}{l}{ }^{2} \text { Rusando Ltd, London, } \\
\text { United Kingdom }\end{array}$} \\
\hline \multicolumn{2}{|c|}{$\begin{array}{l}{ }^{3} \text { Ashridge Middle East, } \\
\text { Ashridge Business School, } \\
\text { United Kingdom }\end{array}$} \\
\hline \multicolumn{2}{|c|}{$\begin{array}{l}{ }^{4} \text { Lancaster University } \\
\text { Management School, } \\
\text { Lancaster University, United } \\
\text { Kingdom }\end{array}$} \\
\hline \multicolumn{2}{|c|}{$\begin{array}{l}{ }^{5} \text { Robertson Cooper Ltd, } \\
\text { Manchester, United Kingdom }\end{array}$} \\
\hline \multicolumn{2}{|c|}{$\begin{array}{l}\text { Correspondence to: } \\
\text { Jill Flint-Taylor }\end{array}$} \\
\hline \multicolumn{2}{|c|}{$\begin{array}{l}\text { Email: } \\
\text { jill.flint-taylor@ashridge. } \\
\text { org.uk }\end{array}$} \\
\hline \multicolumn{2}{|c|}{$\begin{array}{l}\text { Postal address: } \\
\text { Research Departn } \\
\text { Ashridge, Berkhar } \\
\text { Herts. HP4 1NS, } \\
\text { United Kingdom }\end{array}$} \\
\hline \multicolumn{2}{|c|}{$\begin{array}{l}\text { Received: } 29 \text { Apr. } 2013 \\
\text { Accepted: } 15 \text { Apr. } 2014 \\
\text { Published: } 28 \text { Aug. } 2014\end{array}$} \\
\hline \multicolumn{2}{|c|}{$\begin{array}{l}\text { How to cite this article: } \\
\text { Flint-Taylor, J., Davda, A., \& } \\
\text { Cooper, C.L. (2014). Stable } \\
\text { personal attributes and a } \\
\text { resilient approach to work } \\
\text { and career. SA Journal of } \\
\text { Industrial Psychology/ } \\
\text { SA Tydskrif vir } \\
\text { Bedryfsielkunde, 40(1), Art. } \\
\# 1137,10 \text { pages. http:// } \\
\text { dx.doi.org/10.4102/sajip. } \\
\text { v40i1.1137 }\end{array}$} \\
\hline \multicolumn{2}{|l|}{ Read online: } \\
\hline 回辩回 & $\begin{array}{l}\text { Scan this QR } \\
\text { code with your } \\
\text { smart phone or } \\
\text { mobile device } \\
\text { to read online. }\end{array}$ \\
\hline
\end{tabular}

Orientation: Recent research has suggested that personal resilience should be viewed in terms of process and outcome. This has implications for the study of resilience in the work context.

Research purpose: The main research aim was to explore, at a detailed level, relationships between enduring personal characteristics and a resilient approach to work and career.

Motivation for the study: Moving away from the idea of resilience as a specific trait or set of traits raises the question of how general personality and ability constructs influence a resilient approach.

Research approach, design and method: This was an exploratory, quantitative study involving predictor (ability and personality) and criterion (satisfaction and involvement) data for 168 senior managers in five businesses within a retail and distribution group.

Main findings: Evidence was found for differential relationships between personal attributes and a resilient approach (measured in terms of positive vs. negative perspectives on work and career). For example, the personality factor of Openness to Experience was negatively related to Organisation and Career Satisfaction, but positively related to Career and Job Involvement.

Practical/managerial implications: In designing selection, development and employee survey procedures, organisations need to be aware of the differential nature of the relationships between attributes and a resilient approach to work and career.

Contribution/value-add: The study brings together recent research on resilience, personal attributes and work outcomes, and supports the potential of general attribute models for studying and improving the process of developing and exercising a resilient approach in the work context.

\section{Introduction}

The topic of resilience is currently receiving a great deal of attention amongst those who are responsible for sustaining the performance of organisations. In this context, the term 'resilience' has many meanings, including the protection of systems, procedures and resources through disaster planning. Our interest is in personal resilience, also known as psychological resilience, which is defined in more detail below. In this article we seek to bring together and build on two streams of research, the first linking personal attributes with work and career outcomes and the second linking personal attributes with resilience, in the context of wider research on the nature and development of resilience. We review some of the main findings in both areas and report on an exploratory study that investigates how stable personal attributes may be associated with a resilient approach in the context of work pressures and career challenges. Understanding more about these relationships could inform the design of resilience development interventions and enhance their effectiveness.

Recent research suggests that psychological resilience is best conceptualised in terms of process and outcome: the process of working through difficult challenges and the outcome of quicker recovery combined with an increased capacity to cope with pressure (Cooper, Flint-Taylor \& Pearn, 2013; Reich, Zautra \& Hall, 2010). In this view, to which the authors of this article subscribe, resilience may be seen as a multifaceted construct. Rather than referring to resilience as an attribute, we use the term 'resilient approach' to describe the capability that develops from the interplay of personal attributes and experience in the form of both extreme and everyday challenges. This perspective supports the value of developmental interventions, but highlights the need for a good understanding of the relationships between stable personal attributes, the process of developing and exercising a resilient approach and the outcome of an enhanced ability to cope with pressure (see Figure 1). 
The research reported here forms part of a wider study on the prediction of successful outcomes in a career management context. In the wider study, predictor variables were four measures of (reasoning) ability and three dispositional measures. Outcomes were measured in terms of (1) competency-based performance and (2) personal perspectives on work and career (related to satisfaction and involvement). In this article we analyse the relationships between a sub-set of the predictor measures and the personal work and career perspective measures, in light of recent findings from the resilience literature.

\section{Research purpose and objectives}

Our main objective in this exploratory study was to understand more about the relationships between stable attributes and a positive subjective perspective on one's career and current work situation in the context of increased organisational challenges and pressures. Our interest in subjective perspective as a resilience-related measure is based on the definition of stress as arising when pressure exceeds your perceived ability to cope (Palmer \& Cooper, 2010). In measuring work and career perspectives, we draw on research linking workplace stress and well-being with measures of satisfaction, commitment, motivation and involvement (Cooper, Dewe, \& O'Driscoll, 2001; Robertson \& Cooper, 2011).

By using well-established personal attribute models that are not specific to resilience, and by including an ability measure as well as a comprehensive, general model of personality, we seek to identify specific, differential relationships between attributes and work and career experience, in addition to the broad, generalisable relationships that have been found for some of the five-factor model factors (see Figure 2). For example, we expect Conscientiousness to be positively correlated with some but not all of our indicators of a resilient approach to work and career, even though it has been found to be generally related to low stress exposure (Lee-Baggley, Preece \& DeLongis, 2005; Vollrath, 2001). A better understanding of the relationships between stable personal attributes and a resilient approach is a useful starting point for the design of resilience-building interventions in the workplace. It also sets the stage for further exploration of the processes of developing and exercising resilient approaches in the context of different job demands, workplace pressures and career challenges.

\section{Literature review}

\section{Adult resilience and its relevance to the work context}

At an individual level, the term 'resilience' has most commonly been used in the psychological literature to describe the recovery of children experiencing major life changes, deprivation and stress (Masten \& Narayan, 2012; Rutter, 2007). However, there is now a growing interest in the study of resilience in adults, with definitions including 'an outcome of successful adaption to adversity' (Zautra, Hall \& Murray, 2010, p. 4), 'positive adaption in the context of risk or adversity' (Ong, Bergeman \& Chow, 2010, p. 82) and effective coping and adaption although faced with loss, hardship or adversity (Tugade \& Fredrickson, 2004). Masten (2001, p. 235) argues that 'resilience does not come from rare and special qualities, but from the everyday magic of ordinary, normative human resources in the minds, brains and bodies of children, in their families and relationships and in their communities'.

Based on a review of these and other research-based definitions, Cooper et al. (2013, p. 15) define resilience as 'being able to bounce back from setbacks and to keep going in the face of tough demands and difficult circumstances, including the enduring strength that builds from coping well with challenging or stressful events'.

Within the work context, research has suggested that resilience might buffer the negative impact of stress in intrinsically challenging jobs, such as social work (e.g. Howard, 2008). More broadly, the emergence of the positive organisational behaviour approach has highlighted the benefits of resilience across a range of working environments, and found it to be related to performance, satisfaction and organisational commitment (Luthans, Avolio, Avey \& Norman, 2007; Luthans, Norman, Avolio \& Avey, 2008). Research into

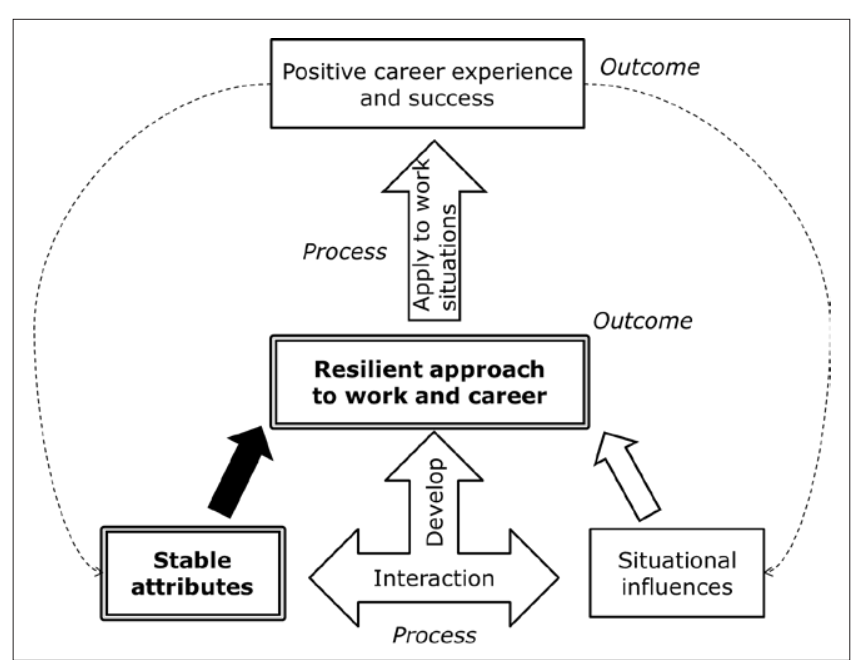

FIGURE 1: Conceptual model - Stable personal attributes and a resilient approach to work and career (emphasising the direct relationships investigated in this exploratory study).

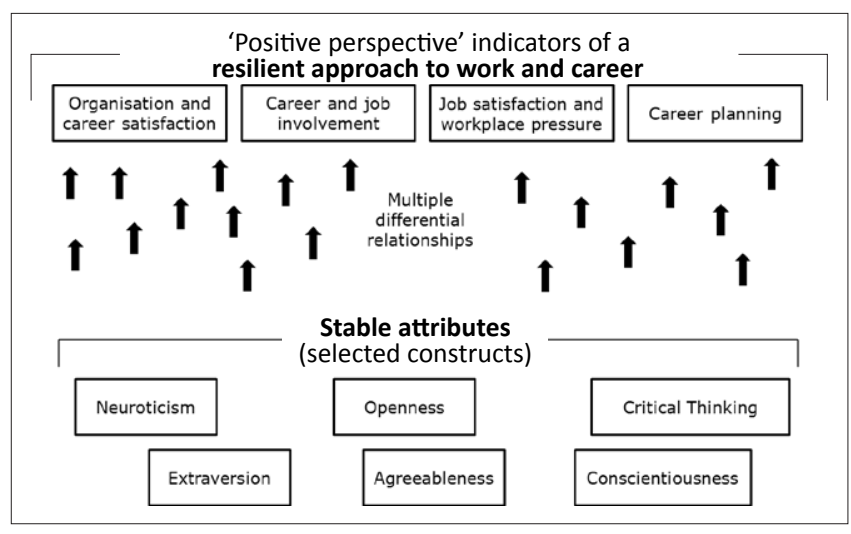

FIGURE 2: Specific elements of the model investigated in this exploratory study. 
the related constructs of hardiness (Kobasa, 1979; Kobasa, Maddi \& Khan, 1982) and mental toughness (Clough, Earle \& Sewell, 2002) has found evidence for relationships with well-being (e.g. Bartone, 1999) and performance (e.g. Bartone, Eid, Johnson, Laberg \& Snook, 2009).

\section{Personal attributes and personal resilience}

Very broadly, the most stable and enduring personal attributes tend to be categorised in terms of ability and personality. Here we summarise some of the main research findings relating intellectual ability and personality to personal resilience.

\section{Intellectual ability}

Research has shown that measures of intellect generally predict good adaptation under adversity (Masten, Burt \& Coatsworth, 2006), although the relationship is a complex one (Masten \& Wright, 2010). For example, there is evidence to suggest that individuals with higher levels of intelligence may be more sensitive to pressure to be successful (Luthar, 2006). One suggestion is that any protective effect relates to personal intelligence, a construct that goes beyond narrow definitions of intellect to include reasoning about personal information, self-concept and life plans (Mayer \& Faber, 2010). Also relevant is research linking measures of intelligence with the personality constructs of Openness to Experience and Achievement in the prediction of creative problem-solving (e.g. Harris, 2004).

\section{Personality}

Within the broader context of resilience research, it may be useful to see personality as a master psychological system that organises mental subsystems, such as motives, thoughts and self-control (Mayer \& Faber, 2010). For the purpose of this article, we focus on the more specific, descriptive framework provided by the five-factor model (FFM) of personality (Costa \& McCrae, 1992; McCrae, 2002). This is a model that is currently of interest to researchers and practitioners in South Africa because of the extensive body of evidence that has been collected for the FFM on a worldwide basis, but also in light of calls for more work to be done to ensure its cross-cultural relevance (Laher, 2013).

Carver and Connor-Smith (2010) reviewed the literature on personality and coping (described as responses to adversity) and highlighted the influence of personality on the frequency of exposure to stressors, the type of stressors experienced and appraisals of stressors. Findings reported in their review include the following: Neuroticism has been found to predict exposure to interpersonal stress and tendencies to appraise events as highly threatening and coping resources as low; Conscientiousness has been found to predict low stress exposure; Agreeableness has been linked to low interpersonal conflict and lower social stress. Within the laboratory situation, a study by Williams, Rau, Cribbet and Gunn (2009) found greater stress resilience to be positively related to Openness to Experience.
Carver and Connor-Smith (2010) also cite research associating a combination of Extraversion, Conscientiousness and Openness to Experience with perceptions of events as challenges rather than threats and with positive appraisals of coping resources. However, they report that a combination of high Neuroticism and low Conscientiousness has been found to predict high stress exposure and a tendency to appraise events as highly threatening.

Other studies have focused on the relationship between the FFM and specific resilience-related constructs known to be related to work outcomes. For example, a number of studies have linked optimism directly to resilience in the work context (Furnham, Sadka \& Brewin, 1992; Proudfoot, Corr, Guest \& Dunn, 2009; Seligman \& Schulman, 1986), whilst optimism shows strong, complex relationships with all FFM factors, apart from Openness to Experience (Sharpe, Martin \& Roth, 2011). The latter study found individual differences in Neuroticism and Extraversion to be responsible for the largest proportional variance in dispositional optimism, although Agreeableness and Conscientiousness demonstrated small levels of incremental validity. In addition, hardiness scores have been found to relate negatively to Neuroticism and positively to Extraversion and Openness to Experience (Maddi, 2002), whilst a consistent negative relationship has been demonstrated between Neuroticism and all mental toughness variables (Horsburgh, Schermer, Veselka \& Vernon, 2009).

Cooper et al. (2013) summarise the range of individual characteristics associated with resilience in the research literature and discuss how these relate to the FFM. The main constructs covered in their analysis are intelligence and problem-solving, self-control, self-awareness, awareness of others and empathy, sociability, conscientiousness, adaptability and ability to improvise, positive emotions, attitudes and beliefs (including optimism, self-belief and confidence) and meaning and sense of purpose.

These authors point out that the relationship between personality and resilience (or coping with adversity) is often investigated by using a short, global measure of personality, which may disguise the specific risks and benefits of particular personality traits in different workplace situations. For example, being well organised and conscientious may help in pre-empting problems and coping with more predictable stressors. However, an individual who favours an unstructured approach and is more open to experience may find it easier to respond in a flexible way and generate creative solutions during times of uncertainty and ambiguity. Therefore, the relationship between an individual's personality and their experience of the work situation is likely to be more complex than might be expected. Viewing resilience in terms of process highlights the point that coping does not simply relate to the presence of a specific personality trait or traits, but also relates to the particular challenging situation that the individual is exposed to. 


\section{Personal attributes and work outcomes}

There are also many studies exploring relationships between personal attributes on the one hand and work outcomes on the other. Here we focus on outcomes related to personal satisfaction, commitment and motivation, which are directly related to the outcome measures in our study. Examples of early findings included a negative relationship between job satisfaction and Neuroticism (Furnham \& Zacherl, 1986) and relationships between work motivation and achievement motivation as well as attributional style (Furnham, 1992). Cropanzano, James and Konovsky (1993) investigated the relationship of both positive and negative affectivity to organisational commitment, turnover intentions, global job satisfaction and performance. Their results included the finding that both negative and positive affectivity were related to global job satisfaction and turnover intentions.

A more recent meta-analytic study found that the individual difference characteristics of Neuroticism and Extraversion help to shape work attitudes such as job satisfaction (Judge, Heller \& Mount, 2002). Although this and other studies have found Extraversion and Neuroticism to be consistently related to satisfaction and commitment in the work context, the evidence also suggests a more complex picture for specific traits and work attitudes. The meta-analysis by Judge et al. (2002) found job satisfaction to be positively related to Extraversion and Conscientiousness and negatively related to Neuroticism, with only the relationship with Extraversion and Neuroticism generalising across studies. Similarly, Erdheim, Wang and Zickar (2006) found evidence for the dispositional basis of organisational commitment, with Extraversion being the only factor significantly related to all three commitment constructs measured in the research.

\section{Comment}

Our review of the literature suggests that there is a rich body of research to draw on in understanding the process of resilience development and how it might build on stable personal attributes to enhance people's experience of their work and career, as well as their performance. However, some of the main streams of evidence are not yet well integrated, and, within occupational research, the role of personal attributes has been studied mainly from the relatively narrow perspective of a few specific constructs such as optimism, hardiness and mental toughness.

Effective personal career management has often been linked to resilience, in view of the many challenges and setbacks that most people encounter in seeking to establish and sustain their career progression. This makes personal career management a useful area to focus on in exploring the relationship between personal attributes, the process of developing and exercising resilience and outcomes in the work context. Previous studies of resilience and career success have tended to present resilience as one of the personal attributes (alongside self-confidence, integrity, etc.) that predict career success (e.g. Poon, 2004). Informed by the research reviewed above, we view resilience in terms of process and outcome and are interested in how stable personal attributes such as self-confidence combine and interact with situational influences to produce a resilient approach to work and career.

As Figure 1 suggests, we expect one element of this to involve direct relationships between stable attributes and a resilient approach to work and career; it is these direct relationships that we investigate here. In summary, the objectives of this study are to explore:

1. differential relationships in the association of personal attributes with positive work and career perspectives

2. the potential of general attribute measures, in particular of a well-researched, narrow bandwidth trait measure of the FFM, to contribute to the understanding of these relationships, in the context of a resilient approach to work and career.

\section{Research design Research approach}

This is a study within the quantitative tradition of validation research, involving the collection and analysis of primary data. It is part of a wider programme of research using a range of predictor and criterion measures to explore relationships between stable personal attributes and a range of outcomes related to the successful performance and career management of senior managers. For the majority of participants, criterion data was collected more than a year after the administration of the predictor measures. Both predictor and criterion variables were subjected to factor analysis as well as to a variety of preliminary data screening techniques and other exploratory analyses. Analysis of the main predictor-criterion relationships in this study involved bivariate correlation and multiple regression.

\section{Research participants}

Participants were senior managers from five retail and distribution businesses that had recently been brought together under the ownership of a corporate group whilst continuing to operate as separate business entities. The context was one of major organisational change that created a variety of challenges and pressures for the senior managers in the study, both directly in relation to the management of their careers and more generally in relation to ensuring the sustained performance of their teams. The extent to which these challenges were perceived as adversity depended on both subjective experience and objective factors affecting each participant's circumstances, but the changing context and new career management procedures meant that all were likely to be subject to an increased level of pressure.

Participants were nominated by their head of business and head of human resources to reflect a wide range of role categories within the top three management grades (roughly in proportion to the numbers of incumbents in those grades, as practical organisational constraints meant it was not possible to use a probability sampling technique). The predictor measures were completed by 205 participants (32 female and 173 male), with 168 completing the criterion measures. 
Ages ranged from 26 to 59 years. Many participants had university qualifications, although a significant number had started work after leaving school. Information was also collected on length of time in current role and with the organisation.

\section{Measuring instruments}

For this study, two predictor measures were selected from the battery of psychometric measures used in the wider research. The revised NEO personality inventory (NEO PI-R) was selected as a well-researched measure of the FFM, providing robust assessment of a comprehensive range of personality constructs at both broad and narrow bandwidth levels (Tett, Steele \& Beauregard, 2003). The Watson-Glaser Critical Thinking Appraisal was selected as a well-validated measure of intellect associated with a wider range of problem-solving abilities than the narrower tests of specific reasoning abilities that made up the other three ability measures in the wider study (Richter, 2011).

NEO PI-R: In their detailed review and discussion of personality assessment, Ozer and Reise (1994, p. 358) described the NEO personality inventory as 'the instrument most closely associated with' the FFM. It may be argued that this position continues to be held by the version used in this study (the NEO PI-R, Costa \& McCrae, 1992). Laher (2013) presents research using the NEO PI-R in the South African context and reports that it is widely used internationally, in both research and assessment practice. McCrae (2002) reports on NEO PI-R data from 36 countries and explores intercultural comparisons and cross-cultural variations. The NEO PI-R measures the five personality factors of Neuroticism $(\alpha=0.92)$, Extraversion $(\alpha=0.89)$, Openness to Experience $(\alpha=0.87)$, Agreeableness $(\alpha=0.86)$ and Conscientiousness $(\alpha=0.90)$. Each factor is represented by six facet scales of eight items each (see Table 1 for facet scale names and internal consistency). For the purposes of this study, factor scores were calculated using the formulae provided in the NEO PI-R manual (Costa $\&$ McCrae, 1992). The questionnaire uses a five-point response scale: strongly disagree, disagree, neutral, agree, strongly agree. Sample item: 'I have a very active imagination'.
The Watson-Glaser critical thinking appraisal: This is a well-established ability measure, which has received a number of positive reviews (e.g. Geisinger, 1998; Kline, 1993). It consists of five subtests: inference, recognition of assumptions, deduction, interpretation and evaluation of arguments. However, the use of subtest scores for in-depth interpretation of an individual's ability is not recommended, due to the small number of items in each subscale (Watson \& Glaser, 1991). The construct represented by an individual's score on the Watson-Glaser test goes beyond comprehension to the critical evaluation of controversial material, and may be related to creative achievement (Anastasi, 1990). On this basis, the Watson-Glaser was considered to be relevant to the kind of problem-solving abilities associated with resilience. The form used here was Form $C(\alpha=0.75)$. Response scales: Test1-true, probably true, insufficientdata, probably false,false; Tests $2-4$ - yes, no; Test 5 - strong, weak (argument).

Criterion measures: A set of 50 self-report items was compiled to measure a range of constructs related to a subjective perspective on work and career, drawing on the research of Cooper et al. (2001), Gould (1979), Mowday, Porter \& Steers (2006), Weiss (2002) and others. In the context of the study these measures are scored to provide 'positive perspective indicators', although they include negatively oriented measures of stress and intention to quit as well as positively oriented measures of satisfaction and so on. For ease of administration, items were split into two questionnaires with all items in Questionnaire A using the same seven-point response scale (strongly disagree to strongly agree), whilst Questionnaire B used a variety of response scales. The two questionnaires were completed by 168 of the original 205 participants, based on availability for this phase of the study.

\section{The 50 items made up a set of seven scales:}

1. Organisational Commitment ( $\alpha=0.85$, sample item 'I really care about the fate of this organisation'); sevenpoint response scale - strongly disagree to strongly agree.

2. Intention to Quit ( $\alpha=0.57$, sample item 'I sometimes feel like leaving this job for good'); seven-point response scale, as above.

TABLE 1: Internal consistency of NEO PI-R facet scales.

\begin{tabular}{|c|c|c|c|c|c|c|}
\hline NEO PI-R factor & NEO facet scale & Facet scale name & $\alpha$ & NEO facet scale & Facet scale name & $\alpha$ \\
\hline \multirow[t]{3}{*}{ Neuroticism } & $\mathrm{n} 1$ & Anxiety & 0.78 & $\mathrm{n} 4$ & Self-consciousness & 0.68 \\
\hline & $\mathrm{n} 2$ & Angry Hostility & 0.75 & n5 & Impulsiveness & 0.70 \\
\hline & n3 & Depression & 0.81 & n6 & Vulnerability & 0.77 \\
\hline \multirow[t]{3}{*}{ Extraversion } & e1 & Warmth & 0.73 & e4 & Activity & 0.63 \\
\hline & e2 & Gregariousness & 0.72 & e5 & Excitement-seeking & 0.65 \\
\hline & e3 & Assertiveness & 0.77 & e6 & Positive Emotions & 0.73 \\
\hline \multirow{2}{*}{ Openness } & 02 & Aesthetics & 0.76 & 05 & Ideas & 0.80 \\
\hline & 03 & Feelings & 0.66 & 06 & Values & 0.67 \\
\hline \multirow[t]{3}{*}{ Agreeableness } & a1 & Trust & 0.79 & a4 & Compliance & 0.59 \\
\hline & a2 & Straightforwardness & 0.71 & a5 & Modesty & 0.67 \\
\hline & a3 & Altruism & 0.75 & a6 & Tender-mindedness & 0.56 \\
\hline \multirow[t]{2}{*}{ Conscientiousness } & $\mathrm{c} 1$ & Competence & 0.67 & c4 & Achievement Striving & 0.67 \\
\hline & $\mathrm{c} 2$ & Order & 0.66 & c5 & Self-discipline & 0.75 \\
\hline
\end{tabular}

$\alpha$, alpha. 
3. Career Future Satisfaction $(\alpha=0.77$, sample item 'This is the ideal career for a life's work'); six-point response scale - strongly disagree to strongly agree.

4. Career Planning ( $\alpha=0.86$, sample item 'I have a plan for my career'); six-point response scale, as above.

5. Career Involvement $(\alpha=0.87$, sample item 'I identify strongly with my chosen line of work'); six-point response scale, as above.

6. Job Satisfaction ( $\alpha=0.83$, sample item [how you feel about] 'The praise I get for doing a good job'); five-point response scale - very dissatisfied, dissatisfied, can't decide, satisfied, very satisfied.

7. Job motivation ( $\alpha=0.50$, sample item 'How involved do you feel in your job'); five-point response scale - circle the appropriate letter (a - e; (a) very little involved, (e) very strongly involved.

\section{Research procedure and ethical considerations}

The predictor measures were administered by the researcher, with each participant attending one of the 23 administration sessions in person. The criterion questionnaires were sent out to most participants approximately 14 months later.

Ethical considerations: Participants were fully briefed on the objective of the study, what their participation would involve and how the results would be used, in order to obtain their informed consent. Strict measures were in place to ensure that individual participants' responses to the criterion questionnaires were kept confidential and not revealed by the researcher to anyone else. These questionnaires were submitted directly to the researcher with responses being stored securely on university-owned computers, using numbers rather than names to identify individual participants.

\section{Statistical analysis}

The analyses were not based on a priori hypotheses, as unexpected and expected (hypothesised) relationships were of equal interest in this exploratory study, which aims to identify differential relationships at both narrow and broad bandwidth levels. However, in a study such as this, which uses multiple predictor and criterion constructs, it is necessary to maintain statistical rigour in interpreting the findings (Blinkhorn \& Johnson, 1990). Therefore, broad bandwidth constructs were created to reduce the number of predictor and criterion variables by using factor scores for the NEO PI-R and for the criterion measures and a single score for the Watson-Glaser.

For the NEO PI-R, factor scores were calculated using weighted facet scale scores, according to a formula provided by Costa and McCrae (1992). For the criterion variables (the positive perspective indicators), factor analyses were carried out using the principal components method with varimax rotation, entering all individual item scores from the two questionnaires (Dunteman, 1989). The best solution was obtained when the number of factors to be extracted was set at four. These are referred to as the 'resilient approach factors', and are numbered 1-4. All the main analyses used these four factors. A few of the results for the individual scales are reported in the discussion, but these should be treated with more caution.

Factor 1: 'Organisation and Career Satisfaction': all organisational commitment, intention to quit and career future satisfaction items (although the first organisational commitment item displayed a loading of 0.34 on Factor 1 and a loading of 0.49 on Factor 2).

Factor 2: 'Career and Job Involvement': all career involvement and job motivation items.

Factor 3: 'Job Satisfaction and Workplace Pressure': 16 out of 20 job satisfaction items (two loaded on to Factor 1 and one on to Factor 2).

Factor 4: 'Career Planning': all career planning items.

Factor 3 was labelled 'Job Satisfaction and Workplace Pressure' because the items mapped closely onto the main sources of workplace pressure found in well-established stress survey scales (Faragher, Cooper \& Cartwright, 2004).

Bivariate correlations and stepwise multiple regression analyses (probability of $F$ to enter $<=0.050$, probability of $F$ to remove $>=0.100$ ) were carried out to explore the relationships between predictor and criterion variables, using the NEO factors, the Watson-Glaser score and the resilient approach factors. The stepwise method was used in order to identify the best combination of independent variables to predict each dependent variable. Listwise deletion was used for missing data, resulting in a smaller $n$ value for some analyses (Everitt \& Dunn, 2001).

The second part of the main analysis involved age, the 30 NEO PI-R facet scales and the overall Watson-Glaser score as independent variables and each of the four career management factors as a dependent variable. Age was included as the exploratory analyses had shown significant relationships with the criterion variables. It was decided to include age in the main regression analyses rather than controlling for it, as age may be considered relevant to resilience and career-related outcomes (see discussion below).

\section{Results}

The correlation analyses showed a number of significant relationships between the predictor and criterion variables. When age was controlled for, all but one of these (the weakest) remained significant, whilst one additional relationship reached significance (NEO factor Agreeableness and Factor 4, Career Planning).

The results of the regression for Organisation and Career Satisfaction indicated that age, four of the NEO facet scales (e3, o2, a2 and n5) and the Watson-Glaser score explained $31.5 \%$ of the variance $\left(R^{2}=0.32, F(6.144)=11.02, p<0.001\right)$. It was found that age significantly predicted Organisation and Career Satisfaction $(\beta=0.38, p<0.001)$, as did assertiveness $(\beta=0.27, p<0.001)$, aesthetic appreciation $(\beta=-0.19, p=0.011)$, straightforwardness $(\beta=0.25, p=0.001)$, 
impulsiveness $(\beta=0.19, p=0.019)$ and critical thinking ability $(\beta=-0.16, p=0.044)$.

The results of the regression for Career and Job Involvement indicated that two of the NEO facet scales (c4 and o5) explained $14.2 \%$ of the variance $\left(R^{2}=0.14, F(2.148)=12.24\right.$, $p<0.001)$. It was found that achievement striving significantly predicted Career and Job Involvement $(\beta=0.29, p<0.001)$, as did openness to ideas $(\beta=0.23, p=0.003)$.

The results of the regression for Job Satisfaction and Workplace Pressure indicated that two of the NEO facet scales (n2 and o1) explained $6.9 \%$ of the variance $\left(R^{2}=0.07, F(2.148)=5.45\right.$, $p=0.005)$. It was found that hostility significantly predicted Job Satisfaction and Workplace Pressure $(\beta=-0.17$, $p=0.042)$, as did imagination $(\beta=-0.17, p=0.046)$.

The results of the regression for Career Planning indicated that age and four of the NEO facet scales $(c 4, a 2,05$ and o1) explained $27.4 \%$ of the variance $\left(R^{2}=0.27, F(5.145)=10.95\right.$, $p<0.001)$. It was found that age significantly predicted Career Planning $(\beta=0.26, p=0.001)$, as did achievement striving $(\beta=0.27, p<0.001)$, straightforwardness $(\beta=-0.26, p=0.001)$, openness to ideas $(\beta=0.25, p=0.002)$ and imagination $(\beta=-0.24, p=0.003)$.

Further regression analyses, looking at the same independent variables as predictors of the original seven dependent variable scales, produced a similar picture but with evidence of additional relationships at this more detailed level. For example, self-discipline (c5) emerged as one of the predictors of organisational commitment $(\beta=0.23, p=0.001)$ and intention to quit $(\beta=-0.25, p=0.001)$, and gregariousness (e2) emerged as one of the predictors of job satisfaction $(\beta=0.20, p=0.013)$. At this level, critical thinking ability was positively related to intention to quit $(\beta=0.24, p=0.001)$ and job motivation $(\beta=0.23, p=0.002)$.

\section{Discussion}

\section{Outline of the results}

This discussion presents and comments on the main points emerging from the study, with a view to setting the scene for further research that addresses directly the question of how a resilient approach may be developed and applied in the context of improving work and career outcomes.

Although age was originally included in the study as a demographic variable, the finding that it is significantly and positively related to certain aspects of participants' perspective on their work and career situation is consistent with the literature on how resilience develops through experience, and more specifically with other research in a management population (Marchant et al., 2008). Interestingly, the latter study found that mental toughness generally increased with age. However, the bivariate correlations reported here show age to be positively related to Organisation and Career Satisfaction $(r=0.38, p<0.001)$ and to Career Planning $(r=0.25, p=0.002)$, but not to Career and Job Involvement $(r=-0.01)$ or Job Satisfaction and Workplace Pressure $(r=0.02)$. Mental toughness is a good example of a specific, resilience-related construct, illustrating the point that a general model of personality may be better suited to exploring the differential nature of the relationship between attributes and a resilient approach.

The results for critical thinking ability support the idea of complex, differential relationships between personal attributes and the 'positive perspectives' indicators. In the supplementary regression analysis, critical thinking ability is significantly, positively related to the specific scale of job motivation $(\beta=0.23, p=0.002)$. However, it is positively related to intention to quit $(\beta=0.24, p=0.001)$ and negatively related to Organisation and Career Satisfaction $(\beta=-0.16, p=0.044)$ in the main regression analysis, results that may possibly be consistent with the finding that people with higher levels of intelligence may be more sensitive to pressure to be successful (Luthar, 2006).

The findings for the NEO PI-R facet scales also caution against looking for a 'resilient profile', which organisations may be searching for during these challenging times. Instead the findings suggest that the question is how specific traits interact with experience and contextual variables to help develop a resilient approach for different situations. For

TABLE 2: Pearson correlation matrix: Bivariate correlations between predictor and criterion variables at the factor/overall score level, and age $(N=156)$.

\begin{tabular}{|c|c|c|c|c|c|c|c|}
\hline Factor & NEO factor $\mathbf{N}$ & NEO factor $E$ & NEO factor $\mathrm{O}$ & NEO FACTOR A & NEO Factor C & Watson-Glaser & Age \\
\hline Factor 1: Organisation \& Career Satisfaction & -0.05 & $0.18^{*}$ & $-0.29 * * *$ & 0.12 & 0.11 & $-0.28 * *$ & $0.38 * * *$ \\
\hline Factor 2: Career \& Job Involvement & -0.02 & 0.07 & $0.17^{*}$ & -0.01 & $0.25^{* *}$ & -0.03 & -0.01 \\
\hline Factor 3: Job Satisfaction \& Workplace Pressure & $-0.16^{*}$ & -0.01 & -0.10 & 0.11 & 0.06 & -0.01 & 0.02 \\
\hline Factor 4: Career Planning & $-0.19 *$ & -0.04 & -0.08 & -0.15 & $0.32 * * *$ & -0.09 & $0.25 * *$ \\
\hline
\end{tabular}

$N$, Neuroticism; e, Extraversion; O, Openness to Experience; c, Conscientiousness.

${ }^{*} p<0.05,{ }^{* *} p<0.01,{ }^{* * *} p<0.001$

TABLE 3: Pearson correlation matrix: Correlations between predictor and criterion variables at the factor/overall score level, controlling for age $(N=147)$.

\begin{tabular}{|c|c|c|c|c|c|c|}
\hline Factors & NEO factor $\mathrm{N}$ & NEO factor $E$ & NEO factor $O$ & NEO factor $A$ & NEO factor C & Watson-Glaser \\
\hline Factor 1: Organisation \& Career Satisfaction & -0.08 & $0.30 * * *$ & $-0.20^{*}$ & 0.03 & 0.04 & $-0.18 *$ \\
\hline Factor 2: Career \& Job Involvement & -0.02 & 0.05 & $0.18^{*}$ & -0.02 & $0.25 * *$ & 0.02 \\
\hline Factor 3: Job Satisfaction \& Workplace Pressure: & -0.16 & 0.01 & -0.11 & 0.11 & 0.05 & 0.01 \\
\hline Factor 4: Career Planning & $-0.22 * *$ & -0.01 & -0.02 & $-0.23 * *$ & $0.28 * *$ & 0.04 \\
\hline
\end{tabular}

$\mathrm{N}$, Neuroticism; e, Extraversion; O, Openness to Experience; A, Agreeableness; C, Conscientiousness.

${ }^{*} p<0.05,{ }^{* *} p<0.01,{ }^{* * *} p<0.001$ 
example, Openness to Experience is negatively related to Organisation and Career Satisfaction, but positively related to Career and Job Involvement. Comparing these findings to some of the most closely related studies, Liao and Lee (2009) also found a positive relationship between Openness to Experience and career involvement, whilst Lounsbury et al. (2003) found a small but positive relationship between Openness to Experience and career satisfaction. The results of our study also suggest what appears to be the new finding that people who are generally straightforward (direct) are more likely to be satisfied with their employer and their career, whilst those who are naturally guarded or manipulative are less easily satisfied and more inclined to actively manage their career. Both could be seen as effective coping styles, depending on the context and the work and career outcome measure that is applied. In a related study, Sutin, Costa, Miech and Eaton (2009) explored the relationships between extrinsic (occupational prestige, income) and intrinsic (job satisfaction) career success and the five-factor model of personality, but did not find a significant relationship between straightforwardness and their intrinsic (satisfaction) measures of career success.

As further evidence for the complexity of these relationships, the results indicate that openness to ideas (o5) is positively related to Career Planning whilst imagination (o1) is negatively related to the same criterion. The latter finding may seem counterintuitive until one considers that low imagination is positively associated with a concern for practicality and effectiveness. Other studies have found it productive to explore such relationships at a narrow bandwidth level (e.g. NEO PI-R facet scales), as well as including analyses of curvilinear relationships, especially in the case of relationships between personality and work outcomes (Vasilopoulos, Cucina \& Hunter, 2007).

One of the most interesting findings is the weak relationship between Neuroticism and the dependent variables. As discussed in the literature review, stronger relationships have been found between Neuroticism and resilience constructs such as optimism and hardiness. However, Lamers, Westerhof, Kovács and Bohlmeijer (2012), report that they found Neuroticism to be the main correlate of psychopathology, with Extraversion and Agreeableness being uniquely associated with positive mental health. When it comes to predicting work outcomes, Neuroticism has been cited in arguments for the situational specificity of personality-job performance relations and for the benefits of a person-situation interactionist model of performance and other work outcomes (Tett \& Burnett, 2003). Also, as reported earlier, Neuroticism has been consistently (negatively) associated with the specific construct of job satisfaction (Judge et al., 2002), but not as consistently with related constructs such as commitment (Erdheim et al., 2006). Therefore, the relationship between Neuroticism and work and career outcomes may be more situation or context specific than previously expected.
As noted above, the statistical analyses were not based on $a$ priori hypotheses. However, reviewing the results at all levels of the analysis showed that there is a high degree of overlap between the attributes associated with positive personal perspectives in this study and the attributes commonly identified with resilience in the literature, as reported by Cooper et al. (2013). In particular, nearly all the NEO facets that were significantly related to the personal perspective factors had a strong conceptual association with one of the four broad groupings of resilience-related attributes drawn from the review and labelled Confidence, Social Support, Adaptability and Sense of Purpose. Further research is needed to investigate and report more conclusively on this aspect of our findings.

Overall, the results support further research based on:

1. recognition and further exploration of the complex, differential nature of the relationship between stable personal attributes and a resilient approach in work and career

2. the idea that a resilient approach to work and career is best understood by investigating how a range of personal attributes (not specific to resilience) contribute to the development and exercising of a resilient approach in different contexts.

\section{Practical implications}

In designing selection and development procedures, criteria should include well-being and satisfaction, in addition to performance measures (Flint-Taylor \& Robertson, 2013; Inceoglu \& Warr, 2011). However, the results of this study suggest that organisations need to be careful about drawing any global conclusions about desirable characteristics. As with the prediction of performance, when considering resilience and a positive career experience it is important to understand specific predictor-criterion relationships at the narrow bandwidth level. The findings also suggest that it may be useful to employ more contextualised forms of assessment, such as situational judgement tests, work sample exercises and so on, rather than relying too heavily on standard measures of ability and personality, which may be insensitive to situational influences.

Another practical implication is that for team-level or even department-level surveys of stress or well-being, it is important to recognise that the survey results are not a pure measure of the situation. As supported by our current findings, they appear to be a measure of the interaction between the individuals in the team or department and their work situation. Whilst this is less likely to be a major factor at the organisation-wide level, it may be quite common for levels of Extraversion or Openness, for example, to be high across a whole team. Our results suggest this could have a marked influence on the team's survey results on Organisation and Career Satisfaction. It is interesting to note, however, that Job Satisfaction and Workplace Pressure are the least affected by dispositional factors. 
With specific reference to the NEO PI-R as a well-established and extensively researched personality measure, the results of this and future studies may encourage its wider use in the South African context. If the NEO PI-R and the FFM can be shown to be helpful in providing a detailed understanding of how personal attributes relate to a resilient approach to work and career, this could add weight to the effort to address the cross-cultural questions mentioned above.

\section{Limitations and recommendations}

Limitations include the fact that all measures were self-report, and there was a general lack of diversity in the senior management population from which the sample was drawn. This was an exploratory study and the design did not allow direct investigation of the interaction between person and situation in the context of the resilience development process. Future research should take account of the likelihood that these relationships are complex in various ways, for example by looking for evidence of curvilinearity.

\section{Conclusion}

The study found evidence for differential relationships between stable personal attributes and a resilient approach to work and career. The findings support further research using FFM and other general attribute measures, alongside more situational measures of work and career experience, to explore the person-situation interaction aspects of the conceptual framework outlined in Figure 1. In doing so, it would be important to take account of recent calls for further study of the widely used and well-validated FFM model from a cross-cultural perspective.

\section{Acknowledgements Competing interests}

The authors declare that they have no financial or personal relationship(s) that may have inappropriately influenced them in writing this article. The original data collection exercise was supported by funding from the W.H. Smith Group.

\section{Authors' contributions}

J.F.-T. (Ashridge Business School and Rusando Ltd) conducted the research study reported in this article. A.D. (Ashridge Business School) reviewed the literature and collaborated on shaping the individual-situation framework and writing the article. C.L.C. (Lancaster University Management School and Robertson Cooper Ltd) helped to frame the work situation, based on his research on the sources of workplace pressure, and commented on drafts of the article.

\section{References}

Anastasi, A. (1990). Psychological testing. New York, NY: Macmillan.

Bartone, P.T. (1999). Hardiness protects against war-related stress in Army reserve forces. Consulting Psychology Journal, 51, 72-82. http://dx.doi.org/10.1037/
Bartone, P.T., Eid, J., Johnson, B.H., Laberg, J.C., \& Snook, S.A. (2009). Big five personality factors, hardiness, and social judgment as predictors of leader performance. Leadership and Organization Development Journal, 30, 498-521. http://dx.doi.org/10.1108/01437730910981908

Blinkhorn, S., \& Johnson, C. (1990). The insignificance of personality testing. Nature, 348, 671-672. http://dx.doi.org/10.1038/348671a0

Carver, C.S., \& Connor-Smith, J. (2010). Personality and coping. Annual Review of Psychology, 61, 679-704.

Clough, P., Earle, K., \& Sewell, D. (2002). Mental toughness: The concept and its measurement. In I. Cockerill (Ed.), Solutions in Sport Psychology (pp. 32-45). London: Thomson.

Cooper, C.L., Dewe, P.J., \& O'Driscoll, M.P. (2001). Foundations for organizationa science: A Sage Publications series: Organizational stress: A review and critique of theory, research, and applications. Thousand Oaks, CA: SAGE Publications.

Cooper, C.L., Flint-Taylor, J., \& Pearn, M. (2013). Building resilience for success: a resource for managers and organizations. Basingstoke: Palgrave Macmillan. http://dx.doi.org/10.1057/9781137367839

Costa, P.T., \& McCrae, R.R. (1992). Revised NEO Personality Inventory and NEO Five-Factor Inventory Professional Manual. Odessa: Psychological Assessment Resources.

Cropanzano, R., James, K., \& Konovsky, M.A. (1993). Dispositional affectivity as a predictor of work attitudes and job performance. Journal of Organizational Behavior, 14, 595-606. http://dx.doi.org/10.1002/job.4030140609

Dunteman, G.H. (1989). Principal Components Analysis. London: Sage.

Erdheim, J., Wang, M., \& Zickar, M.J. (2006). Linking the Big Five personality constructs to organizational commitment. Personality and Individual Differences, 41(5), 959-970. http://dx.doi.org/10.1016/j.paid.2006.04.005

Everitt, B.S., \& Dunn, G. (2001). Applied multivariate data analysis. London: Arnold. http://dx.doi.org/10.1002/9781118887486

Faragher, E.B., Cooper, C.L., \& Cartwright, S. (2004). A shortened stress evaluation too (ASSET). Stress and Health, 20(4), 189-201. http://dx.doi.org/10.1002/smi.1010

Flint-Taylor, J., \& Robertson, I.T. (2013). Enhancing well-being in organizations through selection and development. In R.J. Burke \& C.L. Cooper (Eds.), The fulfilling workplace (pp. 165-186). Farnham: Gower.

Furnham, A. (1992). Personality at work. London: Routledge. http://dx.doi. org/10.1002/job.4030130104

Furnham, A., Sadka, V., \& Brewin, C.R. (1992). The development of an occupational attributional style questionnaire. Journal of Organizational Behavior, 13, 27-39.

Furnham, A., \& Zacherl, M. (1986). Personality and job satisfaction. Personality and Individual Differences, 7, 453-459. http://dx.doi.org/10.1016 /0191-8869(86)90123-6

Geisinger, K.F. (1998). Review of Watson-Glaser critical thinking appraisal. In J.C. Impara, \& B.S. Plake (Eds.), The thirteenth mental measurements yearbook (pp. 1121-1124). Lincoln, NE: Buros Institute of Mental Measurements.

Gould, S. (1979). Characteristics of career planners in upwardly mobile occupations. Academy of Management Journal, 22, 539-550. http://dx.doi. org $/ 10.2307 / 255743$

Harris, J.A. (2004). Measured intelligence, achievement, openness to experience, and creativity. Personality and Individual Differences, 36(4), 913-929. http://dx.doi. org/10.1016/S0191-8869(03)00161-2

Horsburgh, V.A., Schermer, J. A., Veselka, L., \& Vernon, P.A. (2009). A behavioural genetic study of mental toughness and personality. Personality and Individual Differences, 46, 100-105. http://dx.doi.org/10.1016/j.paid.2008.09.009

Howard, F. (2008). Managing stress or enhancing wellbeing? Positive psychology's contributions to clinical supervision. Australian Psychologist, 43, 105-113. http:// dx.doi.org/10.1080/00050060801978647

Inceoglu, I., \& Warr, P. (2011). Personality and job engagement. Journal of Personnel Psychology, 10(4), 177-181. http://dx.doi.org/10.1027/1866-5888/a000045

Judge, T.A., Heller, D., \& Mount, M.K. (2002). Five-Factor Model of Personality and Job Satisfaction: A Meta-Analysis, Journal of Applied Psychology, 87(3), 530-541. $\mathrm{http}: / / \mathrm{dx}$.doi.org/10.1037/0021-9010.87.3.530

Kline, P. (1993). The handbook of psychological testing. New York, NY: Routledge.

Kobasa, S.C. (1979). Stressful life events, personality and health: An inquiry into hardiness. Journal of Personality and Social Psychology, 37, 1-11. http://dx.doi. org/10.1037/0022-3514.37.1.1

Kobasa, S.C., Maddi, S.R., \& Khan, S. (1982). Hardiness and health: A prospective study. Journal of Personality and Social Psychology, 42, 168-177. http://dx.doi. org/10.1037/0022-3514.42.1.168

Laher, S. (2013). Understanding the Five-Factor Model and Five-Factor Theory through a South African cultural lens. South African Journal of Psychology, 43(2), 208-221. http://dx.doi.org/10.1177/0081246313483522

Lamers, S.M.A., Westerhof, G.J., Kovács, V., \& Bohlmeijer, E.T. (2012) Differential relationships in the association of the Big Five personality traits with positive mental health and psychopathology. Journal of Research in Personality, 46, 517-524. http://dx.doi.org/10.1016/j.jrp.2012.05.012

Lee-Baggley, D., Preece, M., \& DeLongis, A. (2005). Coping with interpersonal stress: Role of Big Five traits. Journal of Personality, 73(5), 1141-1180. http://dx.doi. org/10.1111/j.1467-6494.2005.00345.x

Liao, C., \& Lee, C. (2009). An empirical study of employee job involvement and personality traits: The case of Taiwan. International Journal of Economics and Management, 3(1), 22-36. 
Lounsbury, J.W., Loveland, J.M., Sundstrom, E.D., Gibson, L.W., Drost, A.W., \& Hamrick, F.L. (2003). An investigation of personality traits in relation to career satisfaction. Journal of Career Assessment, 11(3), 287-307. http://dx.doi. org/10.1177/1069072703254501

Luthans, F., Avolio, B.J., Avey, J.B., \& Norman, S.M. (2007). Positive psychological capital: Measurement and relationship with performance and satisfaction. Personnel Psychology, 60, 541-572. http://dx.doi.org/10.1111/j.1744-6570.2007.00083.x

Luthans, F., Norman, S.M., Avolio, B.J., \& Avey, J.B. (2008). Supportive climate and organizational success: The mediating role of psychological capital. Journal of Organizational Behavior, 29, 219-238. http://dx.doi.org/10.1002/job.507

Luthar, S.S. (2006). Resilience in development: A synthesis of research across five decades. In D. Cicchetti, \& D.J. Cohen (Eds.), Developmental psychopathology, Vol. 3. Risk, disorder, and adaptation (2nd edn., pp. 739-795). New York, NY: Wiley.

Maddi, S.R. (2002). The story of hardiness: Twenty years of theorizing, research and practice. Consulting Psychology Journal: Research and Practice, 54, 175-185. http://dx.doi.org/10.1037/1061-4087.54.3.173

Marchant, D.C., Polman, R.C.J., Clough, P., Jackson, J.G., Levy, A.R., \& Nicholls, A.R (2008). Mental toughness: Managerial and age differences. Journal of Managerial Psychology, 24, 428-437. http://dx.doi.org/10.1108/02683940910959753

Masten, A.S. (2001). Ordinary magic: Resilience processes in development. American Psychologist, 56, 227-238. http://dx.doi.org/10.1037/0003-066X.56.3.227

Masten, A.S., Burt, K.B., \& Coatsworth, J.D. (2006). Competence and psychopathology in development. In D. Cicchetti, \& D. Cohen (Eds.), Developmental psychopathology, Vol. 3, Risk, disorder and psychopathology (2nd edn., pp. 696-738). New York, NY: Wiley.

Masten, A.S., \& Narayan, A.J. (2012). Child development in the context of disaster, war and terrorism: Pathways of risk and resilience. Annual Review of Psychology, 63, 227-257. http://dx.doi.org/10.1146/annurev-psych-120710-100356

Masten, A.S., \& Wright, M.O. (2010). Resilience over the lifespan: Developmental perspectives on resistance, recovery, and transformation. In J.W. Reich, A.J. Zautra, \& J.S. Hall (Eds.), Handbook of adult resilience, (pp. 213-237). New York, NY: The Guilford Press.

Mayer, J.D., \& Faber, M.A. (2010). Personal intelligence and resilience: recovery in the shadow of broken connections. In Reich, J.W., Zautra, A.J., \& Hall, J.S. (Eds.) Handbook of adult resilience (pp. 94-111). New York, NY: The Guildford Press.

McCrae, R.R. (2002). NEO PI-R data from 36 cultures: Further intercultural comparisons. In R.R. McCrae, \& J. Allik (Eds.), The Five-Factor Model of Personality Across Cultures, (pp. 105-126). New York, NY: Kluwer Academic/Plenum Publishers. http://dx.doi. org/10.1007/978-1-4615-0763-5_6

Mowday, R., Porter, L., \& Steers, R. (2006). Employee organization linkages. New York NY: Academic Press.

Ong, A.D., Bergeman, C.S., \& Chow, S. (2010.) Positive emotions as a basic building block of resilience in adulthood. In J.W. Reich, A.J. Zautra, \& J.S. Hall (Eds.), Handbook of adult resilience (pp. 81-93). New York, NY: The Guilford Press.

Ozer, D.J., \& Reise, S.P. (1994). Personality assessment. Annual Review of Psychology, 45, 357-388. http://dx.doi.org/10.1146/annurev.ps.45.020194.002041

Palmer, S., \& Cooper, C. (2010). How to deal with stress. London Kogan Page.

Poon, J.M.L. (2004). Career commitment and career success: Moderating role of emotion perception. Career Development International, 9(4), 374-390. http:// dx.doi.org/10.1108/13620430410544337
Proudfoot, J.G., Corr, P.J., Guest, D.E., \& Dunn, G. (2009). Cognitive-behavioural training to change attributional style improves employee well-being, job satisfaction, productivity, and turnover. Personality and Individual Differences, satisfaction, productivity, and turnover. Personality and Indivi
$46,147-153$. http://dx.doi.org/10.1016/j.paid.2008.09.018

Reich, J.W., Zautra, A.J., \& Hall, J.S. (Eds.) (2010). Handbook of adult resilience. New York, NY: The Guildford Press.

Richter, L. (2011). Questions about critical thinking: A survey of relevant research. Inquiry, 26(2), 37-43.

Robertson, I., \& Cooper, C. (2011). Well-being at work. London: Palgrave Macmillan.

Rutter, M. (2007). Resilience, competence and coping. Child Abuse and Neglect, 31 205-209. http://dx.doi.org/10.1016/j.chiabu.2007.02.001

Seligman, M.E., \& Schulman, P. (1986). Explanatory style as a predictor of productivity and quitting among life insurance sales agents. Journal of Personality and Social Psychology, 50(4), 832-838. http://dx.doi. org $/ 10.1037 / 0022-3514.50 .4 .832$

Sharpe, J.P., Martin, N.R., \& Roth, K.A. (2011). Optimism and the Big Five factors of personality: Beyond neuroticism and extraversion. Personality and Individua Differences, 51(8), 946-951. http://dx.doi.org/10.1016/j.paid.2011.07.033

Sutin, A.R., Costa, P.T., Miech, R., \& Eaton, W.W. (2009). Personality and career success: Concurrent and longitudinal relations. European Journal of Personality, 23, 71-84. http://dx.doi.org/10.1002/per.704

Tett, R.P., \& Burnett, D. (2003). A personality trait-based interactionist model of job performance. Journal of Applied Psychology, 88, 500-517. http://dx.doi. org/10.1037/0021-9010.88.3.500

Tett, R.P., Steele, J.R., \& Beauregard, R.S. (2003). Broad and narrow measures on both sides of the personality-job performance relationship. Journal of Organizational Behavior, 24(3), 335-356. http://dx.doi.org/10.1002/job.191

Tugade, M.M., \& Fredrickson, B.L. (2004). Resilient individuals use positive emotions to bounce back from negative emotional experiences. Journa of Personality and Social Psychology, 86(2), 320-333. http://dx.doi. org/10.1037/0022-3514.86.2.320

Vasilopoulos, N.L., Cucina, J.M., \& Hunter, A.E. (2007). Personality and training proficiency: Issues of bandwidth-fidelity and curvilinearity. Journal of Occupational and Organizational Psychology, 80(1), 2044-8325. http:// dx.doi.org/10.1348/096317906X102114

Vollrath, M. (2001). Personality and stress. Scandinavian Journal of Psychology, 42(4), 335-347. http://dx.doi.org/10.1111/1467-9450.00245

Watson, G., \& Glaser, E.M. (1991). Watson-Glaser Critical Thinking Appraisal. Sidcup, Kent: The Psychological Corporation Ltd.

Weiss, H.M. (2002). Deconstructing job satisfaction: Separating evaluations, beliefs and affective experiences. Human Resource Management Review, 12, 173-194. http://dx.doi.org/10.1016/S1053-4822(02)00045-1

Williams, P.G., Rau, H.K., Cribbet, M.R., \& Gunn, H.E. (2009). Openness to experience and stress regulation. Journal of Research in Personality, 43(5), 777-784. http://dx.doi.org/10.1016/j.jrp.2009.06.003

Zautra, A.J., Hall, J.S., \& Murray, K.E. (2010). Resilience: A new definition of health for people and communities. In J.W. Reich, A.J. Zautra, \& J.S. Hall (Eds.), Handbook of adult resilience (pp. 3-34). New York, NY: Guilford. 